\title{
NGO Services to Refugees/Displaced Persons in Thailand
}

\author{
by Roger Fordham
}

The year 1975 saw a number of radical changes in the three countries making up Indochina. On April 17, 1975 troops under the leadership of Pol Pot entered Phnom Penh and almost immediately introduced the extremely radical policies which marked the Khmer Rouge rule from 1975 to 1979.

Two weeks later on the April 30, 1975 after a thirty-year war, North Vietnamese troops entered Saigon and, under communism, sought to unify Vietnam.

Later that same year, in December of 1975, a less radical political change took place in Laos and that country, too, came under communism.

These changes resulted in massive outflows of people seeking asylum. Thailand, sharing common borders with both Cambodia and Laos, became a host to refugees from both Laos and Cambodia as well as large numbers of Vietnamese who arrived by boat.

This left Thailand in the unenviable position of having to support these uninvited populations until a solution could be found.

Traditionally the office of the United Nations High Commission for Refugees takes a key role in situations such as this, but there was no office in Bangkok at that time and it was not until September, in response to an invitation by the Royal Thai Government, that the UNHCR established an office in Thailand.

At the same time, a number of aid agencies representing the International community were looking to provide services to the refugee population in Thailand.

In establishing services in a crisis situation and in the absence of a coordinating body, there is a risk of a number of problems occurring. Duplication of services, inappropriate services, lack of continuity, inadequate delivery of services are just a few of the risks involved in an "ad hoc" operation of this magnitude.

In the recognition of these problems, seventeen agencies convened a series of meetings with the aim of establishing a coordinating body and a secretariat whose function would be to liaise with various offices of the Royal Thai Government, international organizations, including the UNHCR, and other non-member agencies. This body was called the Committee for the Coordination of Services to Displaced Persons in Thailand (CCSDPT.)

This body currently has thirtynine member agencies. Although the name indicates that it is a coordinating committee, in fact its real function is more one of providing and facilitating the flow of information.

The autonomy of each member organization is respected and no attempt is made to impose any changes on organizations, but each organization actually undertakes to open every possible avenue of communication so that effective coordination does take place.

Members represent twelve different countries, as well as Thailand, and member agencies meet monthly in two separate sessions. The first is a closed meeting where issues of current interest are raised. This is followed by an open session where Royal Thai Government agencies are present as well as international organizations, such as the UNHCR, the UN Border Relief Operation, the Intergovernmental Committee for Migration and the International Committee of the Red Cross.

In addition to these fora there are subcommittees which deal with specific areas, such as the Medical Subcommittee, the Education Subcommittee, the Karen Subcommittee and, more recently, the Cambodian Liaison Subcommittee. The charter that the NGOs have is clearly one of being service-providers and, as such, they cannot be involved in political policy formulation.

\section{Program philosophies}

The UNHCR has the mandate for finding solutions for refugees under its protection. Those solutions are threefold.

a) Voluntary repatriation to the country of origin once the political situation has become stable.

b) Integration in the country of first asylum where repatriation is not practicable.

c) Resettlement in a third country as a result of negotiations between countries outside of the homeland and the countries of first asylum.

In the case of the Indochinese, the numbers and political considerations were so great that for the first five years only the third solution was 
employed as a durable solution. After that only the Lao cases were provided with the option of repatriation and, even then, only a few were able to return. Until recently, resettlement was regarded as the only realistic longterm solution for most cases.

The nature of the NGO programs reflected this situation. Most people in refugee centres were geared for a life in the West. Education agencies taught, using Western curricula, Western languages. Predominantly English was taught in an effort to assist refugees to meet the language criteria for acceptance by the West. Skills training was geared to provide refugees with marketable skills in the employment arenas of the West and medical programs in the refugee centres mostly reflected the "clinic" model of the West. In the initial stages those programs were realistic and appropriate since resettlement was almost exclusively in Western countries (the United States, Canada, Australia and the European nations).

In the past year, the focus has changed. Ágencies have recognized the situation as being more conducive to voluntary repatriation, with the emphasis being on "voluntary." The Laotian repatriation program has operated more and more efficiently in the last twelve months and has attracted more and more Lao to apply as a result of increased confidence.

From the beginning of 1989, hopes were raised that a political solution would be found in Cambodia and the 300,000 displaced $\mathrm{Khmer}$ inside Thailand would, at last, be able to repatriate. In order to better prepare for this eventuality, the NGOs, under the Coordination of the United Nations Border Relief Operation (UNBRO), implemented a new philosophy, Self-Management, under which the Khmer themselves took a far greater share of responsibility for the programs at a management and decision-making level. The programs still continue on this basis but the optimism that was seen for repatriation has receded as a result of the Paris talks between the Khmer factions in August of last year where the much hoped for political solution failed to materialize.

It should be realized that, for the refugees and the displaced in Thailand, the NGOs are the "face of the West," for they provide the grassroots workers who have optimum contact with the refugees. For this reason it has been really vital that the NGOs address the problem of durable

\section{The new role for ... NGOs should be involvement in general development for the entire population.}

solutions. In continuing to act with a Western approach, on the assumption that people would be resettled, this, in turn, had a psychological effect on the refugee population who were geared mentally to believe that their only option was resettlement. In fact, for the vast majority, the $300,000 \mathrm{Khmer}$ on the border, there is no question but that they will, one day, return to their country of origin. In gearing programs to the level of services, or, at least, the aims of services in their homeland, agencies mentally gear the camp populations for the realities of life at home and creating a positive attitude towards the concept of repatriation.

Another positive development towards repatriation has been the number of agencies who, whilst maintaining a presence in the centres in Thailand, have established services and offices in the home countries. This, in addition to instilling some sort of confidence in refugees considering repatriation, also provides a source of vital information on conditions in the homeland, as many refugees and displaced people left a number of years ago and are essentially out of touch with the current situation.

It can, therefore, be said that although the NGOs play - and should play - no role in an actual political solution, they should stay abreast of political changes and play some role in gearing refugees and the displaced for the solution that is most appropriate for them.

\section{Interaction with the various authorities}

In the early years the refugee centres were under the auspices of the Total Thai Armed Forces and coordination was through the Joint Operations Centre (JOC). In order to obtain approval to operate in a refugee centre, each agency applied to the JOC outlining a program proposal and providing details of staffing and structure. Later, in the early 1980s, some of the centres, those away from strategic borders, came under the authority of the Ministry of the Interior. Currently all camps, with the exception of the Khmer border camps, come under this authority which requires agencies to follow the same type of procedure as did the JOC previously.

All centres having people designated as refugees come under the protection of the UNHCR and each refugee centre has a central coordinator called a field officer. This person is responsible for overseeing 
and assuming responsibility for all UNHCR programs. Many of the NGO programs in the centres are funded by the UNHCR and, as such, come under some supervision by the UNHCR field officer in the refugee centre, although there is a central program and administrative unit based in Bangkok which is responsible for the overall coordination of the programs.

With the exception of two centres on the Khmer/Thai border, all centres in that area come under the coordinating authority of UNBRO as the people in these centres are not designated as refugees but are referred to as Displaced Persons. As such, in general, they are not eligible for resettlement nor for the protection which would normally be accorded to refugees under the UNHCR. In fact, the camp administration in this case comes under the various components of the coalition government as recognized by the United Nations. This government is made up of three factions, the ANS or Sihanoukists, the KPNLF, the Khmer Peoples National Liberation Front under a previous Khmer Prime Minister, Sonn San, and the Khmer Rouge. UNBRO is essentially a service provider to these factions which are viewed by the United Nations as a government in exile. The NGO organizations working in these centres do so on the understanding that they are serving a civilian population, for to do otherwise would implicate them politically. They are humanitarian organizations and cannot become politically involved at all. These NGOs are mostly funded by UNBRO and, as such, submit program proposals to this body for approval annually. As stated previously, UNBRO has instituted a policy of Khmer Self-Management; programs operating in these camps reflect this philosophy.

A good example of this can be seen in the programs initiated by the organization Handicap International. Theirs is essentially a rehabilitation program for amputees, most of whom are war victims. The program is set up in such a way to teach amputees to make their own prostheses out of local materials - bamboo, old car tires and plaster. Khmer technicians are trained and, in turn, amputees go through a program which teaches them to make their own prosthetic limbs. By doing this, victims can return home and still maintain the same level of care provided this side of the border and technicians are able to transfer the necessary skills to their homeland on return whilst being responsible for programs on this side of the border. Because of the obvious political neutrality of this program and its equally obvious appropriateness, it is accepted by all authorities in both UNBRO and the various Khmer administrations.

\section{Beyond the client group}

For anyone who has visited the refugee centres, particularly the Khmer border camps, it becomes obvious that the local population is itself a needs group. A rural community living in the border regions has the normal restrictions one would anticipate in a community distanced from main centres, but, in this case, due to the political situation manifested in frequent shellings, their social and economic situation has been destabilized. It is in this situation that the NGOs also have a role to play. Again, through UNBRO, a program has been established entitled the "affected Thai villages program." These are essentially compensatory programs which recognize the instability of the area and provide services to the local Thai population.

The concept of the Affected Thai Villages Program originated with the the Royal Thai Government and was instituted in October 1978 to assist Thai villagers in the Thai Kampuchean border region for the above reasons.

From 1981, the project was extended to the Thai/Lao, Thai/ Burmese and the Thai/Malaysian borders. In total, 578 villages, or some 600,000 people, benefit from the program, 242 villages along the Lao border, 170 along the Kampuchean border, 94 along the Burmese border and 72 along the Malaysian border.

Once again this is a program of cooperation. Supplementary funding for the program comes from various donor countries, the USA, Japan, West Germany, Canada, Taiwan, Sweden, Norway and Belgium. WEP/UNBRO distribute food and infrastructure support.

The role of the NGOs in this program is to make services, which are available to the refugee/displaced persons populations in the camps, also available to the Thai villages in the region. Some agencies have established education and medical programs in the villages themselves.

\section{Summary}

In essence, it could be said that the role of the NGOs in Thailand is to provide non-political relief and support services to displaced populations whilst either a resettlement solution is found through an appropriate agency or until a political solution is found enabling the displaced to return safely.

As repatriation becomes more of a possibility, there is a need for development programs to work in the countries of origin to assist the weakened economy. Several NGOs are in various processes of evaluation to determine whether or not they have a role in that development, and, if so, what changes need to be made to make their programs developmentbased rather than relief-based. At the same time, it is becoming increasingly obvious that these agencies should not exclusively serve the returnees, as this could only create tensions within the communities and further divide them from the existing populations. The new role for those NGOs should be involvement in general development for the entire population.

Roger Fordham is the Executive Secretary of the CCSDPT in Bangkok. 